\title{
Educação continuada na docência: reflexões \\ a partir de Bourdieu e Gur-Ze'ev
}

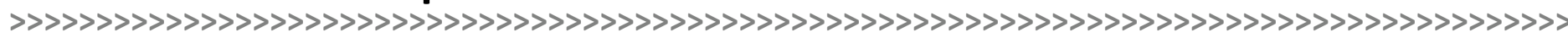

\author{
Denise Dalpiaz Antunes* \\ Alexandre Anselmo Guilherme** \\ Lucas Rech da Silva ${ }^{* * *}$
}

\section{Resumo:}

O texto traz importante contribuição do Pacto Nacional pelo Fortalecimento do Ensino Médio (PNEM), no sentido de aquisição de "capital cultural" e transformação do "habitus" segundo a perspectiva sociológica de Pierre Bourdieu argumentando-se a formação do "professor improvisador", defendido por Ilan Gur-Ze'ev. Ainda, destaca-se a importância deste tipo de ação, especialmente na valorização e melhoria da escola pública, na pessoa dos educadores, além da atualização da práxis. As considerações sobre a importância do capital cultural de Bourdieu $(2004,2013)$ e do professor improvisador de Gur-Ze'ev (2005, 2008, 2010, 2011) são interessantes para um bom entendimento da importância deste tipo de programa. Aponta-se que, sem o apoio de tais ações, a capacidade de indivíduos expandirem seu "capital cultural" é reduzida, comprometendo o potencial para o surgimento e/ou revelar do "professor improvisador", crítico e encorajador da crítica.

\section{Palavras-chave:}

Formação de Professores. Educação Continuada. PNEM. Pierre Bourdieu. Ilan Gur-Ze'ev.

\begin{abstract}
:
This article argues for the contributions of the Pacto Nacional pelo Fortalecimento do Ensino Médio) to the acquisition of 'cultural capital' and transformation of the "habitus" by teachers, which is in accordance to the sociological perspective of Pierre Bourdieu, whilst also noting the appearance of "improviser-teacher" as advocated by llan GurZe'ev. Attention to the importance of this type of action, enhancing and improving state schools, the qualification of educators through helping to develop their practices. The considerations about the importance of "cultural capital" of Bourdieu $(2004,2013)$ and improviser-teacher of Gur-Ze'ev $(2005,2008,2010,2011)$ are interesting for a good understanding of the importance of this type of program. It points out that without the support of such actions, the ability of individuals to expand their "cultural capital" is reduced, compromising the potential for the appearance of the "improviser-teacher" critical and encouraging of criticism.
\end{abstract}

\section{Keywords:}

Teacher Education. Lifelong Learning. PNEM. Pierre Bourdieu. Ilan Gur-Ze'ev.

\footnotetext{
* Doutora e Mestra em Educação pela Pontifícia Universidade Católica do Rio Grande do Sul. Professora Adjunta da Faculdade de Educação da Universidade Federal de Pelotas. E-mail: drdenisedalpiaz@gmail.com
}

\footnotetext{
** > Mestre em Filosofia pela University of St. Andrews. Doutor em Filosofia pela Durham University. Pós-Doutorado pelo Institute of Advanced Studies in Humanity, University of Edinburgh. Professor adjunto do Programa de Pós-Graduação em Educação da PUC-RS. E-mail: alexandre.guilherme@pucrs.br
}

\footnotetext{
*** > Licenciado em Ciências Sociais pela universidade Federal de Pelotas. Mestre e doutorando em Educação pela PUC-RS. E-mail: lucas.rech@gmail.com
} 


\section{Introdução}

Na contemporaneidade, em função da exacerbada velocidade de transformações que a cultura globalizada impõe aos indivíduos, exigências no campo da educação são acentuadas para que o ensino possa atender às demandas dos alunos no século XXI. Especialmente, inter-relações ocorridas através de diálogos verticalizados (tal qual nas redes sociais que fazem parte destas gerações) que precisam acontecer entre educadore e educandos, de modo que essas, possam evoluir para uma escola que se coloque de forma dinâmica, motivadora e estruturada, com professores que "falem a língua", dos estudantes da era digital.

Essas exigências se apresentam não apenas das necessidades dos educandos, mas também dos próprios educadores que carecem de adequadas condições de trabalho, que não possuem salários condizentes para uma educação continuada e que esteja de acordo com as responsabilidades educativas que crescem a cada dia e, para tanto, são necessárias formações específicas para sua professoralidade, ou ainda, formações continuadas que respondam a integralidade do ser humano: uma Educação Continuada ao longo da vida.

Essas e outras adversidades da carreira docente são evidentes, pelas mudanças e exigências aos docentes, especialmente quando adentram no âmbito escolar, ou melhor, na instituição educativa a qual é responsável pelos processos de ensino e de aprendizagem. Instituição essa, que eficazmente, institui, ou deveria instituir, a educandos e educadores as mais diferentes redes de conhecimento em que a sociedade contemporânea está inserida.

Nesse contexto, revela-se também a urgência de formações continuadas de professores que vislumbrem tantas obrigatoriedades e realidades da/na práxis docente, além do autoconhecimento, ou seja, uma Educação Continuada. Conforme já desatacado, uma educação continua que se estabeleça a partir de uma mudança paradigmática no sentido de oportunizar aos professores uma formação integral, com desenvolvimento perm nente de suas possibilidades, que proporcione um autoconhecimento, no caminho da automotivação e auto-realizaç̃ono, na plenitude da vida e especialmente, neste caso, dentro da carreira docente.

Uma educação para educadores, que proporcione amplo diálogo e desenvolvimento, entre pares, dentro do ambiente de trabalho; no locus do ambiente educativo. Num sentido mais amplo, uma educação contínua que possa vislumbre uma cultura solidária e sem intolerância com vistas às ações educativas com as juventudes do atual contexto educativo.

Com estas intencionalidades basilares de formação continua dentro do ambiente escolar, entre outros objetivos, em novembro de 2013, uma portaria governamental ${ }^{1}$ do Ministério da Educação, instituiu o Pacto Nacional pelo Fortalecimento do Ensino Médio (PNEM). Ação que contemplou possibilidades de educação continuada dos professores e coordenadores pedagógicos do Ensino Médio, especialmente para os educadores atuantes na rede pública de ensino, especificamente na rede estadual, no país inteiro, com universidades federais 'pactuadas' com Secretarias Estaduais de Educação (SEDUCs) e Coordenadorias Regionais de Ensino (CREs) nos municípios participantes.

Partindo dessas consideraçoes iniciais, destaca-se que esse texto traz um recorte dos resultados da pesquisa realizada após o término da II Etapa do PNEM, em julho de 2015, no Seminário Estadual, realizado no RS, onde estiveram presentes as seis universidades federais participantes do pacto nesse Estado (UFRGS, UFPel, FURG, UFSM, UFFS, Unipampa). Tal pesquisa surgiu da necessidade de conhecer as concepções dos participantes, a partir do PNEM enquanto política pública de educação, preferencialmente, do entendimento ou não, desse programa enquanto proposta de Educação Continuada.

Além disso, apontar para as possibilidades de continuidade deste tipo de programa ao evidenciar nas falas dos participantes tais intencionalidades e desejos, para uma educação continua de docentes, no locus do trabalho educativo, a qual contemple a realidade da escola, de seus alunos e do entorno social, na qual a escola está inserida. Sobretudo, destaca-se, nas reflexões teóricas, a partir da análise das respostas dos entrevistados a perspectiva .

Ainda, essa política de governo veio de encontro com as Diretrizes Curriculares Nacionais para o Ensino Médio (DCNEM) de 2012, as quais propuseram o início de significativas transformações na estrutura curricular e pedagógica na etapa final da Educação Básica (EB) brasileira. No Rio Grande do Sul, tais Diretrizes embasaram a reforma do Ensino Médio Politécnico ${ }^{2}$ e o PNEM adentra essa reestruturação, atravessando a configuração das ações de formação onde é justamente, pensada de forma interdisciplinar onde o trabalho, a pesquisa e a prática social são tidos como princípios educativos.

Enfatiza-se que com essas e outras tantas mudanças no que concerne às atividades docentes, há que se estabelecer ações de formações permanentes de educadores. Conforme, já destacado aqui arguiremos a ideia de uma Educação Continuada que contemple, muito além dos métodos e didáticas entre processos de ensino e de aprendizagem, uma ação pessoal do aprender ao longo da vida, pela qual educadores possam buscar seus desejos constantes de autoconhecimento com vistas a auto-realização, ao empoderamento docente e uma elevação crítica de sua professoralidade.

Contudo, esse texto busca responder ao questionamento inicial do estudo: Quais contribuições o Pacto Nacional pelo Fortalecimento do Ensino Médio possibilitou aos professores inseridos nesse contexto, aos estudantes nessa modalidade de ensino e as escolas?

\section{Educação Continuada}

A Educação Continuada, elegida neste estudo como paradigma epistemológico configura-se como um pressuposto de integralidade na formação pessoal, no desenvolvimento permanente do indivíduo. Esta é fundamental quando se revelam cada vez mais necessidades educativas diferenciadas e atualizadas, eficazmente no século XXI. Cabe destacar que essa Educação Continuada é muito bem enfatizada por Portal e Franciscone (2007, p. 560), quando refere-se a:

" Processo vital, tendo como característica ser contínuo e permanente.

" É sempre um movimento na busca de algo novo. Não no sentido do inusitado, mas no sentido de agregar conhecimentos que são complementares àqueles que a pessoa já possui.

" Relacionada à trajetória que cada pessoa trilha em sua formação, ao percurso de alguém: fruto de seus interesses, de sua motivação, de sua própria inconformidade com o que possui, do que já dispõe.

"Não se constitui em um conceito novo e sim algo já consagrado, porém com vários significados.

" Educação ao longo da vida: não tem começo, meio e fim e não pode se resumir a seus meros aspectos formais.

Também, nesse pensar, nesse mesmo processo de continuidade de formação permanente, Antunes (2016, p. 84) destaca que "[...] isso nem sempre é oportunizado na instituição educativa". Em muitos espaços educativos nem mesmo um momento destinado para as ações de planejamento entre pares são permitidos, no sentido de tempo efetivo para o encontro com o outro, haja visto a demanda de trabalho que muitos educadores existam espaços pedagógicos, no que diz respeito ao meio escolar, que propiciem momentos de aprendizagens em vivencias, numa partilha com os pares" (ANTUNES, 2016, p. 84). A reforma do EM no Rio Grande do nico em 2012 tro onsino Médio politéc-

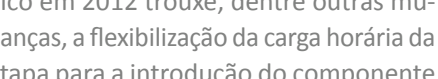
curricular "Seminário Integrador" "que traz pesquisa como princípio metodológico
om carga horária gradual entre os três anos. Tal componente pretende introduZir o trabalho de pesquisa no EM como
uma possibilidade de aperfeiçoamento da etapa e também dos estudantes que vis01.140 de 22 de 
Ainda assim, a mesma autora segue advertindo que a educação continuada "[...] se torna necessária para que a prática educativa seja atualizada, contextualizada, represente modelos positivos ao educando, além de indicar práticas motivadoras na diversidade de alunos da sala de aula" (ANTUNES, 2016, p. 84).

Intencionalmente, no locus da ação pedagógica, no ambiente educativo, na escola, a Educação Continuada, deve perpassar as ações e a vida do educador e de seus pares, el deve buscar a atualização no/do fazer pedagógico, de modo a vislumbrar a ampliação de consciência no sentido de contemplar, reconhecidamente as necessidades de seus alunos e do contexto socioeconômico, no qual estiver inserido a escola. "Como o Ser Humano se encontra em um constante vir-a-Ser, a Educača Continuada passa a ser parte essencil de sua existência" (PORTAL; FRANCISCONE, 2007, p. 559).

Sobretudo, é preciso garantir espaços de aprendizagem para educadores, espaço de vivências e experiências intra e interpessoais de modo que as novas aprendizagen construídas nesses ambientes sejam intrínsecas ao desejo de aprender por toda a vida; as aprendizagens precisam ter "gosto" de vida, ou seja, precisam ser significativas para arem novos motivos ao ensinar e ao aprender, tanto para educadores quanto para educandos. Ora,

[...] as ações humanas, na pessoalidade, no agir de cada pessoa, indicam a motivaçãa pessoal, em que cada indivíduo se encontra e se identifica nas representaçōes sociais culturais do seu meio educacional. Professores, antes disso, são pessoas que precisan encontrar seu propósito de vida, seus objetivos diários de existencialidade, suas metas e desejos a alcançar (ANTUNES, 2016, p. 83).

Destaca-se que a aprendizagem na vida adulta, etapa vivida pelo educador provavelmente, constitui-se importante ação pessoal na existencialidade, principalmente quando essa representa significativamente, uma constante interação com o meio na qual está inserido o adulto, especialmente, o educador no espaço educativo. Constantemente na existência, o ser humano aprende, eficazmente, na medida em que vive, especialmente quando interage com seus pares. "Cada experiência educativa pode provocar diversas aprendizagens”, afirma Undurraga Infante (2004, p. 21, tradução nossa), e diz mais: “[...] a aprendizagem não é um fenômeno exclusivo dos contextos educativos, senão, mais ainda, parte do funcionamento vital do ser humano" (UNDURRAGA INFANTE, 2004, p. 21, tradução nossa).

Nesse sentido de experiência vivida, a Educação Continuada de professores, especialmente dentro da escola, no ambiente escolar, deve ser também de modo a vislumbrar uma formação integral, ativa, vivida da ação criativa com o outro, precisa representar a possibilidade de novas construções pessoais, com sentido de aprendizagens significativas, que possam contribuir para renovados contextos de ensino. Conforme Delors (2003, p. 85), educação integral "[...] é a ideia de um novo modelo de desenvolvimento mais respeitador da natureza e dos ritmos da pessoa".

Sobretudo, a Educação Continuada para professores, deve elencar as possibilidades de renovar as práticas pedagógicas, especialmente quando se refere aos alunos da atualidade. Os quais estão inseridos numa sociedade de constante mudança, principalmente quanto ao conhecimento. Para Lomônaco (2012, p. 7), "[...] a Educação Continuada destaca-se como um instrumento por meio do qual os indivíduos buscam manter-se atualizados numa sociedade que muda muito mais rapidamente do que em décadas passadas".

O mesmo autor, Lomônaco (2012), destaca que é necessário o investimento pessoal de cada educador, quando se fala em educação ao longo da vida, de modo a investir no capital humano. Outrossim, a Educação Continuada, necessita contemplar a atualização particular, para cada indivíduo, indubitavelmente, em seu contexto social. Para tanto,
"[...] educadores, gestores educacionais e professores necessitam criar espaços de formação permanente para capacitar os cidadãos e contribuir para a adaptação às diferentes transformaçoes econômicas, profissionais, sociais, comunicativas e tecnológicas que caracterizam as sociedades em desenvolvimento" (LOMÔNACO, 2012, p. 7).

Assim, essa Educação Continuada de educadores, destacada acima, pode ser o diferencial na vida de cada um, especialmente quando ela contribuir efetivamente na construção da integralidade do ser. Contudo, Portal e Franciscone (2007, p. 560) alertam que "[...] é fundamental que ultrapassemos o conceito primário de Educação Continuada, preocupada apenas com as competências intelectuais do homem para viver no mundo da informação".

Imbernón (2010, p. 78) também contribui com essas ideias afirmando que “[...] a formação pode ajudar a definir esse significado daquilo que se faz na prática em situações concretas e, para se alcançar novos saberes, também permite mudar a identidade e o eu de forma individual e coletiva". Trabalhar na Educação Continuada de modo reflexivo acerca das práticas educativas, pode auxiliar professores a vislumbrar um outro modelo de práxis, de maneira mais condizente com as realidades atuais: um modelo educativo mais motivador para educandos e educadores.

Contudo, a vida humana está repleta de alegrias, satisfações, vontades e motivações. Em contrapartida, mas não dissociadas dos sentimentos anteriores, estão as incertezas, as dúvidas, os desalentos, as frustrações, as crises pessoais, que também compõe o dia a dia da existencialidade do indivíduo como resultados de muitas vivências. Por isso, é preciso que neste percurso cada pessoa, cada educador, encontre e reconheça seus ideais, seu motivos pessoais de vida, constitua-se resiliente nas adversidades, bem como nos desejos à felicidade, no sentido de constituir alegria em viver (ANTUNES, 2016).

Nisso, enfatiza-se que essa educação continua de professores deve abarcar saberes que transcendam os conhecimentos acadêmicos, necessários a educadores, especia mente quanto às diversidades da educação nessa atualidade, saberes que possam torna a educação mais afetiva, mais humana e contextualizada, interessante e motivadora para o estudante. Muito além, alerta-se para uma educação continuada para educadores que carreguem em si a responsabilidade de instituir a tantos educandos um conhecimento capaz de despertar em todos esses, o desejo, o motivo internalizado para uma educação pessoal ao longo da vida.

Nisso tudo, cada vez mais é enfatizado a relevância da formação permanente nas carreiras profissionais. Alerta-se para professores perceberem, compreenderem e internalizarem a necessidade primordial de educação pessoal ao longo da sua trajetória de vida efetivamente naquilo que se constitui do cotidiano das ações do educador no ambiente educativo e, ainda assim, na constituição dos saberes docentes que se edificam no dia a dia da práxis educativa.

\section{A pesquisa}

Nas possibilidades de formação de professores, que neste trabalho é pensada na perspectiva da educação contínua de professores, surge o PNEM, conforme apontado anteriormente, como uma proposta de ação educativa in loco, como uma rede que se estabeleceu,e partindo do compromisso das Instituições de Ensino Superior (IES) federais, SEDUCs, CREs e escolas estaduais da rede pública com seus professores e coordenadores pedagógicos atuantes no ensino médio. O Curso de 200h ocorreu em duas etapas, entre 2014 e 2015, e teve auxílio de cadernos disponibilizados pelo programa. O conteúdo dos cadernos trazia uma abordagem interdisciplinar, possibilitando que assim os professores 
pudessem estar em constante diálogo uns com os outros, pensando atividades colaborativas e interdisciplinares. Sobretudo, o eixo condutor de todo o programa vislumbrava o educando, ou melhor as diferentes expressões da juventude, como o centro das aç̃es pedagogicas que necessitam do olhar diferenciado do educador para construir e edificar o conhecimento.

Assim, dentro do contexto educativo também apontado anteriormente, os professores do Ensino Médio Politécnico do Rio Grande do Sul participantes do PNEM configuraram como os sujeitos participantes desta pesquisa de caráter qualitativo. Minayo (1998, p. 22) remete para uma pesquisa qualitativa aquela que "[...] trabalha com um universo de significados, motivos, aspirações, crenças, valores e atitudes, o que corresponde a um espaço mais profundo das relações, dos processos e dos fenômenos que não podem ser reduzidos à operacionalização de variáveis". A abordagem sócio-antropológica, neste Estudo de Caso, considera os sujeitos e suas particularidades, agentes da pesquisa, os participantes do PNEM.

Em Bogdan e Biklen (1994, p. 47-61), a pesquisa qualitativa traz, em si determinadas características:

» Na investigaç̃̃o qualitativa a fonte direta de dados é o ambiente natural, constituindo o investigador o instrumento principal.

" A investigação qualitativa é descritiva. Os dados recolhidos são em forma de palavras ou imagens e não números.

Os investigadores qualitativos interessam-se mais pelo processo do que simplesmente pelos resultados e produtos.

"Os investigadores qualitativos tendem a analisar os seus dados de forma indutiva.

" O significado é de importância vital na abordagem qualitativa.

A opção pelo Estudo de Caso se fundamenta na seleção desta política pública de formação de professores, com um grupo de professores atuantes dentro da etapa final da Educação Básica no Rio Grande do Sul. Guiado por esse referencial para solucionar as indagações eas necessidades iniciais de informação, aponta-se para um específico estudo investigativo que, de acordo com Castro (1994, p. 61), seria um estudo de caso

[...] pois, ele apresenta as condições de conter as descrições densas [...] um retrato da situação estudada [...]. Oferece também a possibilidade de apresentar as múltiplas concep̧̧̃̃es que emergem do estudo realizado. O estudo de caso é considerado a forma ideal de relatório de pesquisa para o paradigma naturalista.

Os dados deste texto são, nesse sentido, resultados de um trabalho de campo realizado durante o II Seminário Estadual do PNEM que aconteceu em Julho de 2015 na cidade de Porto Alegre, como encerramento da segunda etapa do PNEM. Os dados foram coletados através de questionário de perguntas abertas que instigaram os sujeitos a descrever suas percepções sobre o programa, a influência do mesmo no ambiente escolar através das práticas desenvolvidas nas oficinas pedagógicas ofertadas pelo PNEM e sua avaliação pessoal do programa. Posteriormente sistematizados pela análise de conteúdo (BARDIN, 2004), sendo esse o processo investigativo aqui trabalhado

Assim, os participantes do III Seminário Estadual, através de questionário simples de perguntas abertas, responderam as seguintes questões de pesquisa: 1. Em sua opinião o que significou participar do PNEM? 2. O que você destacaria como positivo e negativo no programa? 3. Qual a sua avaliação do PNEM enquanto política pública de formação continuada? Nesse sentido, o PNEM alcançou o objetivo de instituir-se como um espaço de formação/educação continuada no ambiente escolar? Que outras contribuiç̃es o PNEM possibilitou aos professores, estudantes e as escolas de um modo geral? Quais desafios ainda se revelam nessa realidade?
Buscando responder estas questões levanta-se neste trabalho três variáveis destacadas nas respostas dos 440 questionários coletados no III Seminário Estadual do PNEM no RS. Primeiramente, avalia-se a importância do paradigma da Educação Continuada na docência através das respostas conferidas ao questionário. A seguir, levanta-se uma importante contribuição que o programa introduz no campo da educação, no sentido de aquisição do capital cultural e transformação do habitus segundo a perspectiva sociológica de Pierre Bourdieu (2013) enquanto argumentando sua importância para a formação do 'professor improvisador', tão debatido por Ilan Gur-Ze’ev (2010b), importante filósofo da educação israelense.Dentro da possibilidade de formação no ambiente educativo proporcionada pelo PNEM, Pierre Bourdieu em sua obra e trajetória mostra que é no espaço escolar onde se reproduzem as condições sociais dos indivíduos: desigualdades privilégios, injustiças. Através de seu arcabouço teórico é possível compreender como se estruturam os mecanismos de reprodução na sociedade.

E provavelmente por um efeito de inércia cultural que continuamos tomando o sistema escolar como um fator de mobilidade social, segundo a ideologia da éscol libertadora’, quando, ao contrário, tende a mostrar que ele é um dos fatores mais eficazes de conservação social, pois fornece a aparência de legitimidade às desigualdades sociais, e sanciona herança cultural e o dom social tratado como dom natural (BOURDIEU, 2013, p. 45)

A produção teórica de Bourdieu é profícua e extensa e por isso, neste momento apropria-se dos conceitos de capital cultural e hábitus para, a posteriori, encontrar na pesquisa realizada quais as contribuições que o PNEM traz ao corpo docente das escolas públicas de nível médio as quais atende, ao campo educativo.

Em Bourdieu, a noção de capital remete a três tipos que extrapolam a noção puramente econômica defendida por Marx, são eles: (1) econômico - salário, renda, capital monetário -, (2) cultural - acesso a bens culturais, saberes, títulos acadêmicos - e (3) social -conjunto de relações sociais. Todas essas formas de capital são convertidas a outra formas de capital, formando então, a noção ampla de capital simbólico. Por exemplo, o capital econômico pode ser convertido em capital cultural porque possibilita ao individuo acessar bens culturais, como livros, teatro, cinema e mesmo uma formacão acadêmica: o capital economico pode ainda ser convertido em capital social na medida em que possibilita acesso a um grupo social, aos lugares frequentados por esse grupo, aos 'gostos' desse grupo. Isso pode ser pensado de maneira diferente, de modo que o capital social pode ser convertido em capital economico e cultural já que o seu grupo social possibilita a criação de 'networks', os quais dão acesso a oportunidades de trabalho, carreira bem como de eventos e informações culturais. Bourdieu comenta a ligação do capital econômico, cultural e social na seguinte citação:

[...] O capital econômico [...] e o capital cultural [...] forma de que revestem as diferentes espécies de capital quando percebidas e reconhecidas como legítimas. Assim os agentes estão distribuídos no espaço social global, na primeira dimensão de acordo com o volume global de capital que eles possuem sob diferentes espécies, e, na segunda dimensão, de acordo com o peso relativo das diferentes espécies de capital, econômico e cultural, no volume total de seu capital (BOURDIEU, 2004, p. 154, grifo nosso).

Ainda, quando se remete especificamente ao capital cultural, o qual é fundamental para nosso argumento nesse artigo, Bourdieu afirma que: 
A maior parte das propriedades do capital cultural pode inferir-se do fato de que, em seu estado fundamental, está ligado ao corpo e pressupoe sua incorporação. A acumulação de capital cultural exige uma incorporação que, enquanto pressupốe un trabalho de inculcação e de assimilação, custa tempo que deve ser investido pessoalmente pelo investidor [...]. Sendo pessoal, o trabalho de aquisição é um trabalho do "sujeito" sobre si mesmo [...] (BOURDIEU, 2013, p. 83)

O capital cultural, segundo Bourdieu (2004), pode ser encontrado em três configurações distintas: incorporado, objetivado e institucionalizado. No estado incorporado, o capital cultural advém de uma herança hereditária, a capacidade de comunicação, de domínio da linguagem e do acesso a informação que se reproduz na instância familia de socialização, é a ponte entre o conhecimento oriundo da instituição familiar e instituição escolar. O estado objetivado, por sua vez, é a apropriação de bens culturais como livros, esculturas, pinturas, cursos, acesso ao cinema, ao teatro, a instrumentos musicais que proporcionam ao sujeito um domínio e uma compreensão da cultura. Está intrinsecamente ligado ao capital monetário, pois apenas o capital econômico é capaz de proporcionar essa apropriação. O capital institucionalizado acontece através do capital econômico na obtenção de diplomas e títulos, que por sua vez garante a apropriação de capital econômico e este é determinado pela instituição escolar.

Quanto a noção de habitus, constitui-se em um sistema amplo, complexo, aberto estruturante da estrutura dos campos e capitais simbólicos. Ou seja, são as ações, disposições, interações, práticas e vivências que dão significado e configuram, dentre outras coisas, o próprio capital cultural. Além disso:

[...] as representações dos agentes variam segundo sua posição [...] e segundo seu habitus como sistema de esquemas de percepção e apreciação. [...] O habitus é ao mesmo tempo um sistema de esquemas de produção de práticas e um sistema de esquemas de percepcão e apreciação das práticas. E, nos dois casos, suas operaç̃ó exprimem a posição social em que foi construído (BOURDIEU, 2004, p. 158).

Portanto, é claro e perceptível a estreita relação entre ambos os conceitos e como o habitus constitui os diferentes capitais simbólicos e o capital simbólico o próprio habitus. E ambos são fundantes da noção de campo, pois não é possível pensar os três conceitos basilares de Bourdieu dissociadamente. "O capital cultural é um ter que se tornou ser, uma propriedade que se fez corpo e tornou-se parte integrante da 'pessoa' [...]. Aquele que o possui pagou com sua própria pessoa e com aquilo que tem de mais pessoal, seu que o possui pagou com sua propria
tempo" (BOURDIEU, 2013, p. 83).

Partindo da clareza destas noções tão importantes no espectro teórico de Pierre Bourdieu busca-se, agora, na escrita dos sujeitos participantes da pesquisa usada para iluminar as ideias expressas neste trabalho, a relação entre os conceitos de Bourdieu e as ações que o PNEM realizou no período de vigência. As citações aqui referidas são também respostas ao questionário aplicado no III Seminário Estadual do PNEM. Ao todo foram aplicados 440, conforme destaque anterior, num total de 28 Coordenadorias Regionais de Educação.

Assim sendo, neste momento, se apresenta um recorte de uma das variáveis da pesquisa em que se realiza uma interpretação e uma categorização da escrita dos sujeitos participantes em uma análise de viés qualitativo. São apresentadas explanações coletadas nos questionários que remetem aos conceitos de Bourdieu que ousamos nos apropriar. dade e completude das falas dos sujeitos, visto que muitas se repetiram ou se colocaram de forma muito similar. Quando questionados sobre o significado de participar do PNEM os sujeitos afirmam que:

" [...] Essa proposta de formação assemelhou-se com uma especialização, pois tive apoio de uma Formadora que era uma professora orientadora, material de leitura com respaldo bibliográfico (cientifico, estudei, montei apresentações, aprendi a usar novas tecnologias, tive banca, meus colegas que me questionavam e além de precisar contribuir com meu trabalho) e me deu subsídios para escrever. (Sujeito n. $25,28^{\mathrm{a}} \mathrm{CRE}$ )

" É Necessária e obrigatória para que realmente tenhamos uma discussão enquanto processo de construção de uma escola de qualidade. A educação é fundamental para este processo contínuo de crescimento. (sujeito n. ${ }^{\circ} 9,1^{a} \mathrm{CRE}$ )

Nesse ponto, evidencia-se que o PNEM possibilitou uma mudança na práxi docente. Tratando-se de um curso de 200h, onde a maioria das formacões ocorreram no ambiente escolar e de forma colaborativa entre os pares, o programa significou, até certo (aço das políticas de formac̃o continuada no sentido da oportunidade revelada. Ou seja, através dessa Educação Continuada, pode-se afirmar que ocorreu uma transformação do capital simbólico que, por sua vez, possibilita uma transformação da prática cotidiana com um novo olhar para os processos educativos, ocorrendo, então, uma mudança nos valores subjetivos destes sujeitos no que confere a ação do ensinar e ai, especificamente, pode-se pensar uma mudança de habitus professoral (SILVA, 2005) que constitui, a posteriori, uma mudança gradual no campo da educação.

Nesse sentido o programa parece que também possibilitou o surgimento do e/ ou revelou o professor improvisador (improvisor), tão argumentado por Gur-Ze'ev, em seu projeto de contra-educação. Contra-educação é o termo criado por Gur-Ze'ev para diferenciar seu projeto da pedagogia crítica de Freire, McLaren, Giroux e Apple, que julga falida, principalmente pela falta de autocrítica e pela busca de utopias impossíveis. De acordo com Gur-Ze'ev a pedagogia crítica enfrenta dois problemas: 1. cria uma visão reduzida da realidade, agora dividida em oprimidos e opressores (GUR-ZE'EV, 2010a, p. 4), procurando realizar uma utopia (por exemplo, a libertação dos oprimidos através da conscientização de Freire); 2. e assim, se torna incapaz de se autocriticar porque julga ter todas as respostas para os problemas da realidade (GUR-ZE'EV, 2005), ficando miope na procura da realização de uma utopia.

Assim, Gur-Ze'ev (2010b, p. 43) descreve seu projeto de contra-educação, que pode-se dizer ser um desenvolvimento da pedagogia crítica, como sendo caracterizado por "[...] uma criatividade aberta e não controlada, responsável e liberal para com a diferença do outro, dando nascimento a uma constituição que abraça o desconhecido e a auto-superação"; e o professor improvisador da contra-educação como sendo "[...] sem um eu-egoístico que quer iniciar a colonização do outro" (tradução nossa). Desse modo, o professor improvisador de Gur-Ze’ev permanence fiel a crítica, é critico, encoraja criticismo, e tudo pode ser sujeito de critica. De acordo com Gur-Ze’ev é esse processo de crítica contínua que transforma a realidade, não a procura de utopias, objetivos que nos cegam, seja lá qual forem.

Isso diferencia o professor improvisador de Gur-Ze'ev do professor na visão de Freire, o professor político. O professor político de Freire procura implementar a utopia da libertação pela conscientização dos oprimidos, mas nessa procura dois problemas podem emergir. Primeiro, alguém, no caso sempre o professor, sabe o que o outro tem de saber para se libertar, para cessar de ser oprimido; e segundo, nesse movimento de procurar a libertação usa o outro como meio para atingir essa utopia da libertação, que não pode ser criticada por ser parte fundamental do projeto. Quer dizer, nessa procura por utopias, a pedagogia crítica acaba por se tornar uma educação bancária já que não 
admite que o outro pense de forma diferente, que o outro seja critico do projeto, já que tem todas as respostas.

Nesse sentido, o professor improvisador de Gur-Ze'ev não enfrenta os mesmos problemas, pois permanece sempre crítico e a favor da critica, mas sem procurar utopias. A possibilidade de critica e a falta de utopias podem gerar um desconforto, mas o desconforto faz parte do processo de educação porque é através dos desafios, da auto-superação que se gera o crescimento. A metáfora de uma caravana atravessando o deserto, fazendo e criando seus caminhos, escolhendo seus destinos, onde os membros dessa caravan estão sempre juntos e em movimento é usada constantemente por Gur-Ze'ev como forma de explicar o que ocorre na educação (cf. GUR-ZE'EV, 2011, p. 38-39); quer dizer, én processo, uma jornada na direção de um horizonte que nunca chega, nos levando a vários destinos no caminho. A falta de destino, o vagar, pode ser algo desconfortável no começo mas Gur-Ze'ev chama a nossa atenção ao desfrutar os momentos, as paradas, a jornada. Há indícios desse entendimento nas respostas de alguns participantes do PNEM que afirmam a importância da critica e do desconforto que a possibilidade da reflexão caus:

"Uma formação continuada que até então foi e espero que continue sendo uma das melhores que proporcionaram para os professores. Momento de discussão, reflexão e ação, tentando sempre pensar no aluno, realidade em que estamos enfrentando no momento. Essa formação renovou o espirito de coragem, garra e amor que existe dentro de cada um de nós professores. (Sujeito n. ${ }^{\circ} 8,7^{\mathrm{a}} \mathrm{CRE}$ )

"Um espaço que foi construído para que possamos pensar, refletir e modificar nossa prática. Excelente. (Sujeito 1, 13a CRE)

"Um ótimo começo para desacomodar os profissionais da educação. (Sujeito n. ${ }^{\circ}$ sem CRE identificada)

Essas afirmações nos ajudam a entender que a busca pela transformação é um constante movimento de criação e re-criação, são estados temporários, consequências de estados particulares da realidade - e a contra-educação, a educação critica, e o professor improvisador, o professor critico, são fundamentais para o processo de transformação. Entretanto, não se procura concretizar uma utopia de modo que nosso mundo se torne perfeito; antes, o que se procura é apenas possibilitar a condição humana, o ser criativo e critico (GUR-ZE'EV, 2008, p. 383). Apesar de ter sofrido criticas fundamentadas, como a dissonância do calendário escolar com os encontros programados, o programa consegue, de certa forma, dar apoio à busca pela transformação.

\section{Conclusões prospectivas: avanços e desafios}

Considerando as inúmeras adversidades que o atual contexto brasileiro impõe à sociedade e à escola, cabe enfatizar o quão importantes e necessárias são as iniciativas que proporcionem aos docentes uma educação permanente, que o possibilite dar continuidad a sua trajetória de desenvolvimento profissional, intelectual e pessoal. A qualidade da educação está intrinsecamente alinhada às questões que dizem respeito à valorização dos processos individuais e coletivos dos educadores que hoje se encontram em sala de aula. Mesmo na existência de inúmeros problemas estruturais, a qualidade do capital humano, quando valorizado de forma ampla e plena, pode contornar as questões puramente físicas do ambiente escolar de forma criativa e colaborativa.

Essa política pública, que pensamos sob o paradigma de Educação Continuada na docência, promove essas possibilidades tão otimistas para um cenário onde se depositam as esperanças para um mundo melhor, mas que na sua pura realidade é, ainda caótico se pensado do quanto ainda desperdiçamos de talentos e potencialidades. É inegável que ainda há muito que avançar no tema. Programas como este devem fazer parte da pauta do campo da Educaç̃o e estarem continumente em processo de revisão e de adequação adveridadeanteirmenteciads para geracional que hoje existe entre educandos e educadores desapareça, proporcionando que ambos possam construir conhecimento e resolver as questões pertinentes aos contextos em que estão inseridos.

As consideraçoeses sobre a importância do capital cultural de Bourdieu e do professor improvisador de Gur-Ze’ev são interessantes para um bom entendimento de quão impor-

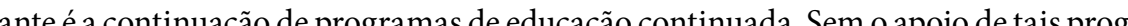
a capacidade de indivíduos expandirem seu capital cultural é reduzida e com isso fica comprometido o potencial para o surgimento e/ou revelar o professor improvisador, crítico e encorajador da crítica. Não sendo assim, abrimos espaço para o professor propagandista, autoritário e desinteressado.

E perceptível nas respostas dos 440 professores participantes desta pesquisa, atuantes no PNEM, os quais responderam ao questionário, quanto a avaliação do Programa, hă unanimidade em ressaltar a importância dessa ação governamental, especialmente quanto a oportunidade de formação pessoal. As respostas destacam, além da urgência de manter esse tipo de formação na escola, entre outras relevâncias pessoais, o reflexo observado e percebido por todos no ambiente educativo, principalmente, os alunos.

E possível refletir essa política de governo como um início para renovadas práticas educativas que, no avançar cotidiano destas práticas, possibilitará mudanças significativas no campo da educação. E se tratando de Brasil, sabe-se que as mudanças são lentas e demandam um esforço paulatino dos agentes envolvidos no processo educativo, um "trabalho de formiguinha" que passa de um para o outro e vai consolidando uma forma diferente de conceber a educação escolar.

\section{Referências}

ANTUNES, Denise Dalpiaz. Oficinas Pedagógicas Cooperativas. A motivação docente na formação continuada. Curitiba: Editora CRV, 2016

BARDIN, Laurence. Análise de Conteúdo. Lisboa: Ediçōes 70, 2004

BOGDAN, Robert; BIKLEN, Sari. Investigação qualitativa em Educação. Porto: Porto, 1994.

BOURDIEU, Pierre. Espaço social e poder simbólico. Coisas Ditas. São Paulo: Brasiliense, 2004

Escritos de Educạ̧ão. Organização Maria Alice Vergueiro e Afranio Catani. 14. ed. Petrópolis, RJ: Vozes, 2013

CASTRO, Marta Luz Sisson. Metodologia da Pesquisa Qualitativa: Revendo as Ideias de Edgon Guba. In: ENGERS, Maria Emília. Paradigmas e Metodologias de pesquisa em Educação: notas para reflexão. Porto Alegre: EDIPUCRS, 1994. p. 53-64.

DELORS, Jacques. Educação: um tesouro a descobrir. Relatório para a UNESCO da comissão Internacional sobre a Educação para o século XXI. São Paulo: Editora Cortez, 2003

GUR-ZE'EV, Ilan. Critical Theory and Critical Pedagogy Today: Toward a New Critical Language in Education. Haifa: Israel, 2005.

Diasporic philosophy, Counter Education and Improvisation: a Reply. Studies in Philosophy and Education, v. 27, n. 5, p. 381-386, 2008.

The Possibility/Impossibility of a New Critical Language in Education. Rotterdam: Sense Publishers, 2010a.

The Nomadic Existence of the Eternal Improviser and Diasporic Co-Poiesis Today. In: . Diasporic Philosophy and Counter Education. Rotterdam: Sense Publishers, 2010b. 
. The Nomadic Existence of the Eternal Improviser and Diasporic Co-Poiesis in the Era of Mega-Speed. In: . Diasporic Philosophy and Counter-Education. Rotterdam: Sense Publishers, 2011. p. 29-45.

IMBERNÓN, Francisco. Formação continuada de professores. Porto Alegre: Artmed, 2010.

LOMÔNACO, José Fernando B. Apresentação à edição brasileira. In: LÓPEZ-BARAJAS ZAYAS, Emilio. O Paradigma da Educação Continuada. Porto Alegre: Penso Editora, 2012.

MINAYO, Maria Cecília de Souza (Org.). Pesquisa Social: teoria, método e criatividade. Petrópolis: Vozes, 1998. p. 9-29.

PORTAL, Leda Lísia Franciosi; FRANCISCONE, Fabiane. Contribuições da Educação continuada na construção da inteireza do ser. Educação, Porto Alegre, v. 63, n. 3, p. 557-569, set./dez. 2007.

SILVA, Marilda da. O habitus professoral: o objeto dos estudos sobre o ato de ensinar na sala de aula. Revista Brasileira de Educação, n. 29, maio/ago. 2005.

UNDURRAGA INFANTE, Consuelo. Como aprenden los adultos? Santiago: Ediciones Universidad Católica de Chile, 2004 